\title{
Quench-Hardening Mechanism Based on the Electrical Properties in Non-Stoichiometric NiTi*
}

\author{
By Toshiyuki Suzuki** and Katashi Masumoto**
}

\begin{abstract}
In order to clarify the cause of quench-hardening in Ni-rich $\mathrm{NiTi}$, the relation between composition and electrical resistivity, and the change in the electrical resistivity at a constant rate of heating for NiTi have been measured.

On the Ni-rich side of the stoichiometry, the electrical resistivity increases with increasing nickel content for waterquenched specimens and remains constant at non-stoichiometric composition for slowly cooled specimens. The measurements of electrical resistivity at a constant rate of heating for water-quenched Ni-rich NiTi show a significant decrease in the electrical resistivity around 300 and $700^{\circ} \mathrm{C}$. Above $700^{\circ} \mathrm{C}$ the electrical resistivity changes in the same manner as slowly cooled specimens. Activation energies were $1.1 \mathrm{eV}$ for the low temperature reaction and $3.7 \mathrm{eV}$ for the high temperature reaction. The electrical resistivity for the specimens of stoichiometric composition and those containing 55 at $\% \mathrm{Ni}$ after being ordered just below the critical temperature increases with increasing temperature. No significant change in the electrical resistivity due to the order-disorder transformation or the eutectoid reaction was observed.

The analysis of the results of the electrical resistivity measurement indicates that the ordered NiTi phase is stable but has a restricted homogeneity range at low temperatures, the precipitation of $\mathrm{Ni}_{3} \mathrm{Ti}$ in the water-quenched state is hardly conceivable and the existence of the order-disorder transformation and the eutectoid reaction is improbable. Therefore, it can be concluded that the quench-hardening in non-stoichiometric NiTi is due to the existence of structure defects.
\end{abstract}

(Received September 7, 1973)

\section{Introduction}

One of the present authors predicted in a preceding paper $^{(1)}$ that the quench-hardening in Ni-rich NiTi is due to the existence of excess point defects which are introduced by the deviation from the stoichiometric composition at quenching temperature. It is well known that the hardness of non-stoichiometric $\mathrm{NiAl}$ and $\mathrm{CoAl}$ depends upon the concentration of structure defects which exist even at room temperature ${ }^{(2)}$. In $\mathrm{NiTi}$, however, quenching from a relatively high temperature is required to retain the high temperature phase which contains structure defects, because the homogeneity range of the NiTi phase is wide at high temperature but restricted at ambient temperature. In addition to the defect hardening, the effects of the order-disorder transformation and the eutectoid reaction on the hardness of non-stoichiometric NiTi must be considered, though the existence of these reactions in the NiTi phase is still not clear ${ }^{(1)(3)}$. As reported by Sastri and Marcinkowski ${ }^{(4)}$, under certain conditions the precipitation of $\mathrm{Ni}_{3} \mathrm{Ti}$ or an intermediate phase prior to the formation of $\mathrm{Ni}_{3} \mathrm{Ti}$ may occur in the as-quenched state and may also become a cause of hardening in the NiTi phase.

In the present investigation, therefore, the electrical resistivity of the NiTi phase was measured to evaluate the existence of the order-disorder transformation and the eutectoid reaction, and the occurrence of precipitation since these reactions affect drastically the electrical resistivity of alloys in general. On the basis of the results of electrical resistivity measurements, the phase diagram in the vicinity of the NiTi phase is

* This paper was originally published in Japanese in $\mathrm{J}$. Japan Inst. Metals, 36 (1972), 796.

** National Research Institute for Metals, Meguro-ku, Tokyo, Japan.

Trans. JIM established to experimentally validate the proposition of defect hardening. Also, the existence of the orderdisorder transformation and the eutectoid reaction in the NiTi phase and the occurrence of the precipitation of $\mathrm{Ni}_{3} \mathrm{Ti}$ in the water-quenched state are discussed.

\section{Experimental}

Samples were prepared by non-consumable arc melting under gettered argon. Electrolytic nickel $(99.9 \% \mathrm{Ni})$ and sponge titanium $(99.8 \% \mathrm{Ti})$ were used as starting materials. Six ingots having compositions varying from 50 to 55 at $\% \mathrm{Ni}$ in steps of $1 \%$ were melted. The ingots obtained were about $100 \mathrm{~g}$ in weight. There was no significant material loss $(<0.1 \%)$ during arc melting. Nominal compositions are, therefore, used throughout the present experiment unless otherwise noted. All ingots were sealed in evacuated quartz ampoules and annealed for more than $25 \mathrm{hr}$ at $1000^{\circ} \mathrm{C}$ to ensure homogenization. The ingots were then canned in mild steel and forged on a conventional forging press at 900 to $1000^{\circ} \mathrm{C}$. The specimens for electrical resistivity measurements were prepared from the forged plate by spark machining. In order to normalize, all the specimens were sealed in evacuated quartz ampoules and annealed for $1 \mathrm{hr}$ at $1000^{\circ} \mathrm{C}$ prior to further heat treatments. All the heat treatments were carried out under a vacuum of $2 \times 10^{-5} \mathrm{mmHg}$. For rapid cooling the heat-treated specimens were quenched by breaking the ampoules under water as mentioned in the preceding paper ${ }^{(1)}$.

The changes in electrical resistivity with temperature were measured. The electrical resistivity was measured by the conventional potentiometric method with four probes. For current and potential lead, copper wires were spot-welded on the specimens having $3 \times 5 \times 100$ $\mathrm{mm}$ in dimensions. The specimens settled in a silica 
tube were heated up to $1000^{\circ} \mathrm{C}$ at a constant rate of $100^{\circ} \mathrm{C} / \mathrm{hr}$ under a dynamic vacuum of $5 \times 10^{-5}$ $\mathrm{mmHg}$, for special cases. The heating rate could be held constant over the whole temperature range by using a program-controlled temperature controller and a slide transformer. The potential measurements were carried out in forward and reverse current directions to prevent the effect of the thermoelectric power generated between copper and NiTi. The temperatures of the specimens were measured between the forward and reverse measurements. Metallographic observations were also conducted on the specimens given the same heat treatment as in the electrical resistivity measurements.

\section{Experimental Results}

The changes in the electrical resistivity of NiTi with temperature for water-quenched and furnace-cooled specimens containing 50 to $55 \mathrm{at} \% \mathrm{Ni}$ on heating at a constant rate of $100^{\circ} \mathrm{C} / \mathrm{hr}$ are shown in Fig. 1. The resistivity change is given by the ratio of resistivity measured at each temperature and at $1000^{\circ} \mathrm{C}$ $\left(R / R_{1000}\right)$. In stoichiometric $\mathrm{NiTi}$, the electrical resistivity of both specimens increases in the same manner with temperature regardless of the different heat treatments and a well defined "Knick" was observed around $100^{\circ} \mathrm{C}$ which is considered to be due to the martensitic transformation. Above the transformation temperature the electrical resistivity increases linearly with increasing temperature. In Ni-rich NiTi, however, the electrical resistivity at room temperature is increased by quenching and the change in the electrical resistivity becomes rather complicated. At 51 at $\% \mathrm{Ni}$, the rate of increase in the electrical resistivity for the water-quenched specimen becomes slow around $300^{\circ} \mathrm{C}$ and then the resistivity coincides with that of the furnace-cooled specimen at $400^{\circ} \mathrm{C}$. For the specimens containing more than 52 at $\% \mathrm{Ni}$, the electrical resistivity also chaniges around $700^{\circ} \mathrm{C}$ in addition to the low temperature change at $300^{\circ} \mathrm{C}$. The electrical resistivity of the water-quenched specimens, therefore, coincides with that of the furnacecooled specimens after these two resistivity changes. The amount of increase in the electrical resistivity at room temperature due to quenching increases with increasing nickel content and reaches almost $50 \%$ at 55 at $\% \mathrm{Ni}$. On the contrary, though the rate of increase in the electrical resistivity becomes faster at $750^{\circ} \mathrm{C}$ for the specimens containing more than 53 at $\% \mathrm{Ni}$, the electrical resistivity of the furnace-cooled specimens increases rather monotonically with increasing temperature.

Figure 2 shows the relation between electrical resistivity and composition of the NiTi phase for the water-quenched and furnace-cooled specimens. It is well known that stoichiometric NiTi undergoes martensitic transformation near room temperature. The electrical resistivity at room temperature was, therefore, obtained by the extrapolation from that of the high temperature phase having a $\mathrm{CsCl}$ type struc-

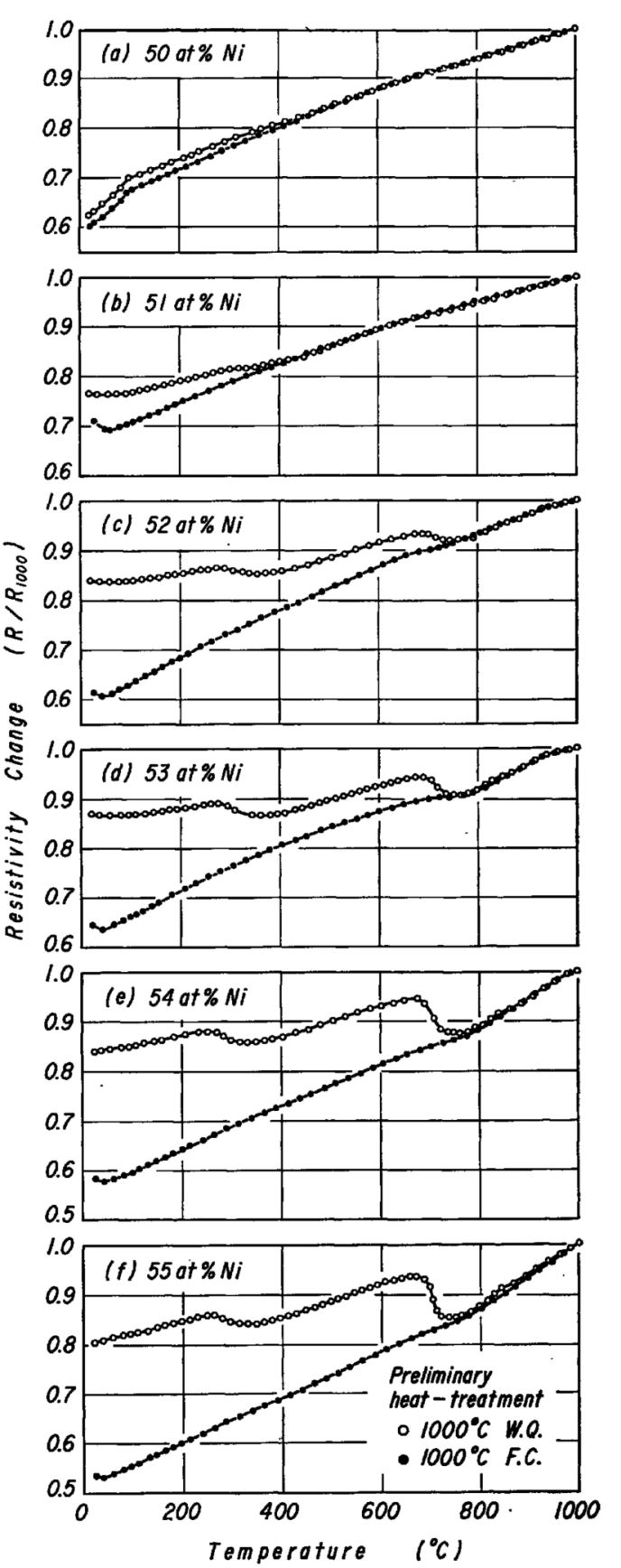

Fig. 1 Changes of electrical resistivity with temperature for non-stoichiometric NiTi. Heated at a constant rate of $100^{\circ} \mathrm{C} / \mathrm{hr}$ after the preliminary heat-treatments.

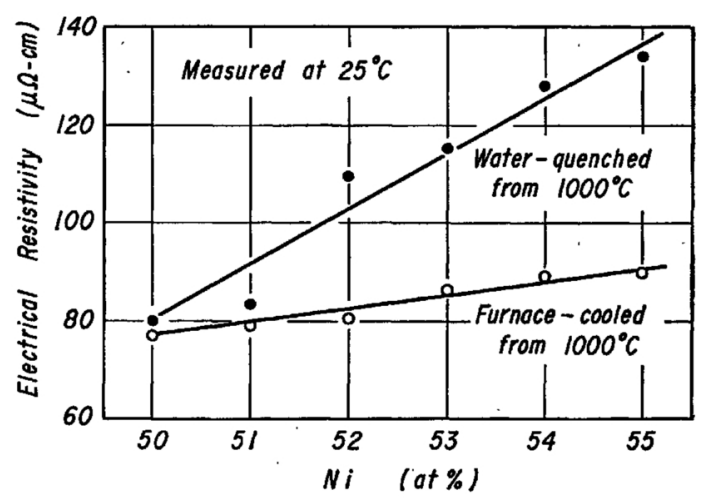

Fig. 2 Relation between electrical resistivity and composition for NiTi Phase. 
ture. The electrical resistivity of the water-quenched specimens increases with nickel content. The electrical resistivity of the furnace-cooled specimens also increases with nickel content though the extent is much smaller. This suggests that the equilibrium state cannot be obtained by furnace cooling for the Ni-rich NiTi as expected from Fig. 1.

Figure 3 illustrates the effect of quenching temperature on the characteristics of the electrical resistivity for the NiTi containing 55 at $\% \mathrm{Ni}$ on heating. The room temperature resistivity increases with increasing quenching temperature. The resistivity change occurring in two steps can be seen in each waterquenched specimen at different temperatures, though the magnitude of the change decreases with decreasing quenching temperature. The results of the constant rate of heating experiments (Figs. 1 and 3) show that when the quenching temperature or the composition is fixed the increase in the electrical resistivity at room temperature depends upon nickel content or quenching temperature, respectively.

As shown in Figs. 1 and 3, two resistivity changes are observed in the temperature-resistivity curves for the water-quenched Ni-rich NiTi. Since these facts seem to suggest that two different precipitation processes are involved, further resistivity measurements were carried out at $50^{\circ} \mathrm{C} / \mathrm{hr}$ and $200^{\circ} \mathrm{C} / \mathrm{hr}$ to obtain the activation energies of the reactions. The results are shown in Fig. 4. The changes in electrical re-

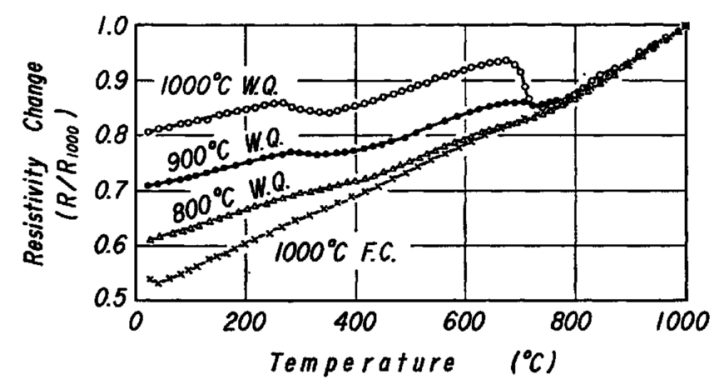

Fig. 3 Effect of quenching temperature on the temperature dependence electrical resistivity of NiTi containing 55 at $\% \mathrm{Ni}$. Heated at a constant rate of $100^{\circ} \mathrm{C} / \mathrm{hr}$.

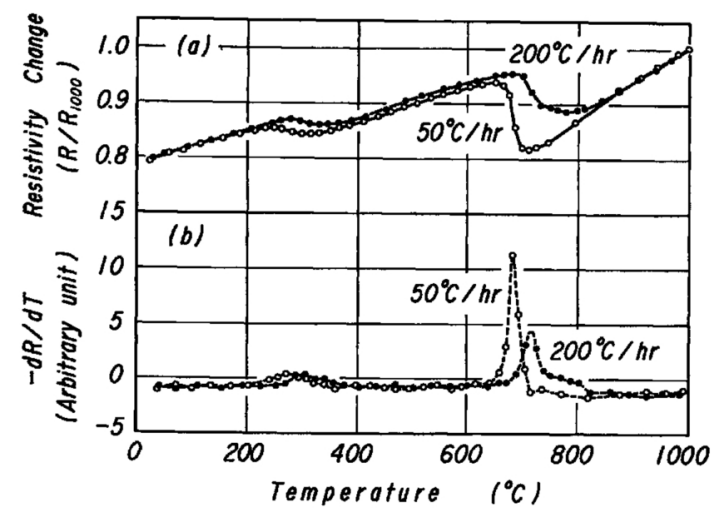

Fig. 4 Constant rate of heating experiments for $\mathrm{NiTi}$ containing 55 at $\% \mathrm{Ni}$ to determine activation energies. (a) changes of electrical resistivity with temperature at two different heating rates, (b) derivatives of (a). sistivity with temperature given by the resistivity ratio on the basis of the resistivity at $1000^{\circ} \mathrm{C}$ are illustrated in Figure 4(a). Figure $4(\mathrm{~b})$ is the derivative of (a). The characteristic temperatures of both processes shift towards the high temperature side as the heating rate increases. These two characteristic temperatures obtained from Fig. 4 are 270 and $685^{\circ} \mathrm{C}$ at $50^{\circ} \mathrm{C} / \mathrm{hr}$, and 300 and $715^{\circ} \mathrm{C}$ at $200^{\circ} \mathrm{C} / \mathrm{hr}$. From these values the activation energies can be calculated as $1.1 \mathrm{eV}$ for the low temperature reaction and $3.7 \mathrm{eV}$ for the high temperature reaction by using the equation ${ }^{(5)}$,

$$
E=k \ln \left(\frac{\alpha_{2} T_{1}^{2}}{\alpha_{1} T_{2}^{2}}\right) /\left(\frac{1}{T_{1}}-\frac{1}{T_{2}}\right),
$$

where $T_{1}$ and $T_{2}$ are the temperatures at which identical values of super-saturated defects are achieved at heating rates $\alpha_{1}$ and $\alpha_{2}$, respectively, and $k$ is Boltzmann's constant.

The latter value $(3.7 \mathrm{eV})$ is identical to the activation energy of nickel self-diffusion in Ni-rich NiAl which was reported by Hancock and $\mathrm{McDonnell}{ }^{(6)}$, and of self-diffusion of transition metals having a $b c c$ structure.

The change in electrical resistivity with temperature for stoichiometric NiTi is shown in Fig. 5. The specimen was water-quenched from $1000^{\circ} \mathrm{C}$ and annealed for $100 \mathrm{hr}$ at $600^{\circ} \mathrm{C}$ which was slightly below the order-disorder transformation temperature and the eutectoid reaction temperature proposed by Wang

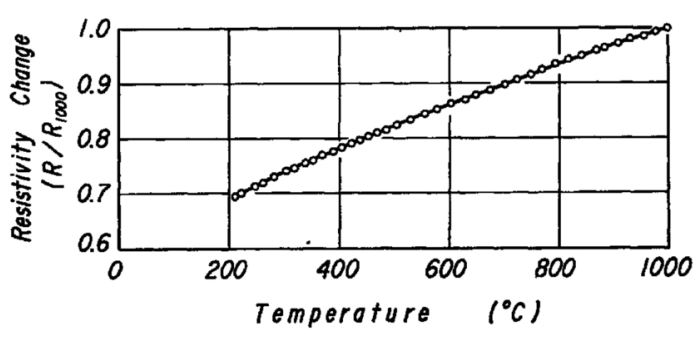

Fig. 5 Change of electrical resistivity with temperature for $\mathrm{NiTi}$ containing $50 \mathrm{at} \% \mathrm{Ni}$. Heated at a constant rate of $100^{\circ} \mathrm{C} / \mathrm{hr}$ after water-quenching from $1000^{\circ} \mathrm{C}$ and annealing at $600^{\circ} \mathrm{C}$ for $100 \mathrm{hr}$.

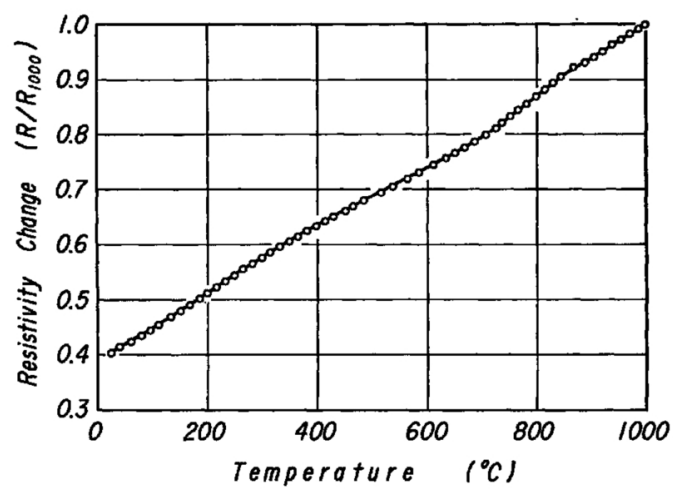

Fig. 6 Change of electrical resistivity with temperature for NiTi containing $55 \mathrm{at} \% \mathrm{Ni}$. Heated at a constant rate of $100^{\circ} \mathrm{C} / \mathrm{hr}$ after water-quenching from $1000^{\circ} \mathrm{C}$ and annealing at $600^{\circ} \mathrm{C}$ for $100 \mathrm{hr}$. 
et al. ${ }^{(7)}$ and Koskimaki et al. ${ }^{(3)}$, respectively. The specimen was then slowly cooled to $200^{\circ} \mathrm{C}$ to prevent the occurrence of the martensitic transformation ${ }^{\dagger}$ and heated at a constant rate of $100^{\circ} \mathrm{C} / \mathrm{hr}$. The electrical resistivity increases linearly with temperature without any anomalous changes.

The change in electrical resistivity with temperature for NiTi containing 55 at $\% \mathrm{Ni}$ is also shown in Fig. 6. The specimen was heat-treated in the same manner as the stoichiometric NiTi and cooled slowly to room temperature. Since the absolute value of the electrical resistivity of annealed specimen is less than that of the furnace-cooled specimen shown in Fig. 1, it is considered that the precipitation of $\mathrm{Ni}_{3} \mathrm{Ti}$ or $\mathrm{Ni}_{3} \mathrm{Ti}_{2}$ is already completed by the annealing. The change in the electrical resistivity with temperature is almost linear except the range between 500 and $800^{\circ} \mathrm{C}$.

\section{Discussion}

\section{Cause of the increase in electrical resistivity by quenching}

From the electrical resistivity measurements it becomes clear that although a little increase in the electrical resistivity occurs by quenching in stoichiometric NiTi, the electrical resistivity of Ni-rich NiTi increases markedly and the amount depends upon nickel content and quenching temperature. Since this tendency agrees very well with the behavior of hardness ${ }^{(1)}$, the findings on the origin of the resistivity increase by quenching may give important information on the mechanism of quench-hardening.

Now, let us consider qualitatively the relation between electrical resistivity and composition of nonstoichiometric intermetallic compounds. In case a superlattice is formed over entire temperature range, the electrical resistivity must change with the composition because the number of structure defects is minimum at stoichiometry and increases with the deviation from this composition. Measurements for the relation between electrical resistivity and composition for several intermetallic compounds having a $\mathrm{CsCl}$ type structure have been made and, in fact, the electrical resistivities increase with the deviation from the stoichiometric composition ${ }^{(8) \sim(10)}$. On the other hand, when the compound phase has a disorder structure at all temperatures or the disorder structure can be obtained by quenching even if the orderdisorder transformation occurs at an intermediate temperature, a different relation must be given. The disordered phase can be treated as a random solid solution in which no structure defects exist except thermal vacancies and which, therefore, obeys the theory of Nordheim ${ }^{(11)}$. In equiatomic compounds having a wide homogeneity range the electrical resistivity always decreases as the composition deviates from stoichiometry. When an ordered structure is

$\dagger$ The highest martensitic transformation temperature is $166^{\circ} \mathrm{C}$ as was reported by Wang et al..$^{(7)}$ obtained by slow cooling, the same relation holds as in all ordered structure.

In the foregoing section we discussed the relation between electrical resistivity and composition on the basis of a phase diagram in which the compound has a wide homogeneity range. Next, we consider a more complicated situation which occurs when the homogeneity range is restricted at lower temperatures. If an ordered structure is formed at all temperatures and the non-stoichiometric compound can be carried over to room temperature by quenching without any precipitates, the relation must be the same as for the wide homogeneity range at all temperatures discussed above. When the compound phase is cooled slowly, the electrical resistivity is constant at all compositions because the matrix approaches a stoichiometric composition as the result of precipitation. If the compound phase has a disordered structure at all temperatures, it is considered that the electrical resistivity obeys the theory of Nordheim ${ }^{(11)}$ in the quenched state and keeps constant within the homogeneity range in the slowly-cooled state. When the order-disorder transformation takes place at an intermediate temperature the relation must be the same as the quenched state for the all disordered structure and the slowly-cooled state for the all ordered structure. Anyhow, the increase in the electrical resistivity of non-stoichiometric compounds by quenching must be observed when the compound phase has an ordered structure at all temperatures or the order-disorder transformation takes place at an intermediate temperature.

Finally, assuming the existence of an eutectoid reaction we consider the relation between electrical resistivity and composition. If the compound phase has an ordered structure, the electrical resistivity must increase with deviating composition from stoichiometry in the quenched state because the decomposition of the compound phase is prevented by quenching. On the contrary, when the compound phase is cooled slowly, the change in the electrical resistivity depends upon that of new phases produced by the eutectoid reaction. The electrical resistivity, therefore, increases with composition in some cases and decreases in others. When the compound phase has an disordered structure, the electrical resistivity decreases with composition in the quenched state and the change in the electrical resistivity depends upon that of the products of the eutectoid reaction in the slowly-cooled state. In general, the rate of the solid state reaction with the diffusion of solute atoms is considered to be relatively slow. Hence it is doubtful that the eutectoid decomposition is completed during the slow cooling (for instance, $80^{\circ} \mathrm{C} / \mathrm{hr}$ at $650^{\circ} \mathrm{C}$ ). There is the possibility that a significant amount of the compound phase is retained in this heat treatment. If so, the electrical resistivity may depend mainly upon that of the compound phase.

As shown in Fig. 7, the relation between electrical resistivity and composition of the compound phase can be classified into eight cases depending upon three proposed phase diagrams for the Ni-Ti system ${ }^{(1)}$ and 


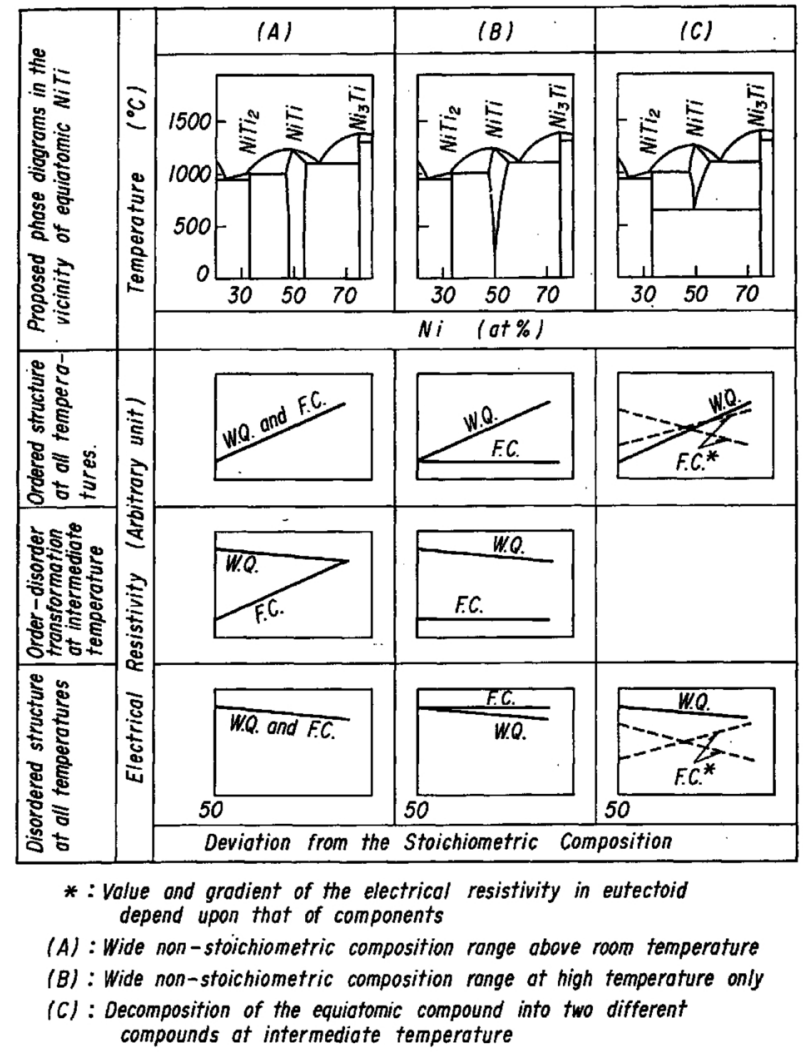

Fig. 7 Schematic representation of the relation between electrical resistivity and composition in NiTi phase for different type of phase diagrams.

the formation of superlattice.

It is clear that the results shown in Fig. 2 coincide with the relation deduced from the phase diagram in which the homogeneity range of the NiTi phase becomes narrower with decreasing temperature and the superlattice is formed at all temperatures. But it is also probable that the ordered phase decomposes into two compounds by the eutectoid reaction.

Quenched-in vacancies are considered to be an additional factor affecting the electrical resistivity of the quenched NiTi phase. The effect of the vacancies, however, can be neglected because the concentration of the vacancies depends mainly on the quenching temperature, and the concentration is much less than that of structure defects ${ }^{(12)}$.

On the basis of the discussion above the extreme increase in the electrical resistivity in Ni-rich NiTi by quenching can be explained by the quenched-in structure defects which are introduced by the deviation from the stoichiometric composition in the ordered NiTi phase at the quenching temperature.

The possibility of the existence of the orderdisorder transformation and the eutectoid reaction will be discussed again later (IV-3).

\section{Changes in electrical resistivity at constant rate of heating}

The electrical resistivity of water-quenched $\mathrm{Ni}$-rich NiTi increases with temperature, accompanied by two distinct resistivity changes, and then coincides with that of the furnace-cooled specimen at a constant rate of heating. The activation energies of the reactions were determined as $1.1 \mathrm{eV}$ and $3.7 \mathrm{eV}$ for the low and high temperature reactions, respectively. In this section we discuss the cause of the two resistivity changes.

In the preceding section it becomes clear that there is no order-disorder transformation in the NiTi phase and the nickel supersaturated NiTi phase (excess nickel atoms form structure defects) can be retained at room temperature. Precipitation of an equilibrated phase must, therefore, occur on heating. If the phase diagram proposed by Wasilewski et al. ${ }^{(13)}$ is correct, the following reactions occur on heating:

(1) annihilation of quenched-in thermal vacancies,

(2) precipitation of $\mathrm{Ni}_{3} \mathrm{Ti}_{2}$ (below $625^{\circ} \mathrm{C}$ ),

(3) $\mathrm{Ni}_{3} \mathrm{Ti}_{2} \rightarrow \mathrm{Ni}_{3} \mathrm{Ti}+\mathrm{NiTi}$ (reverse peritectoid reaction, above $625^{\circ} \mathrm{C}$ ),

(4) precipitation of $\mathrm{Ni}_{3} \mathrm{Ti}$ (above $625^{\circ} \mathrm{C}$ ).

According to the temperature at which the resistivity changes occur, the low temperature reaction (around $300^{\circ} \mathrm{C}$ ) must be due to (1) or (2) and the high temperature one (above $650^{\circ} \mathrm{C}$ ) due to (3) or (4). As shown in Photo. 1 no significant precipitates are observed in the specimen quenched from $600^{\circ} \mathrm{C}$ though its precipitation process is thought to proceed to an intermediate stage, but many precipitates appear in the specimen quenched from $800^{\circ} \mathrm{C}$. In the metallographic observations the specimens were heated up to the quenching temperature in the same manner as for electrical resistivity measurements. The results show that the low temperature reaction is due to (1) or (2) again, and the high temperature reaction due to (4).
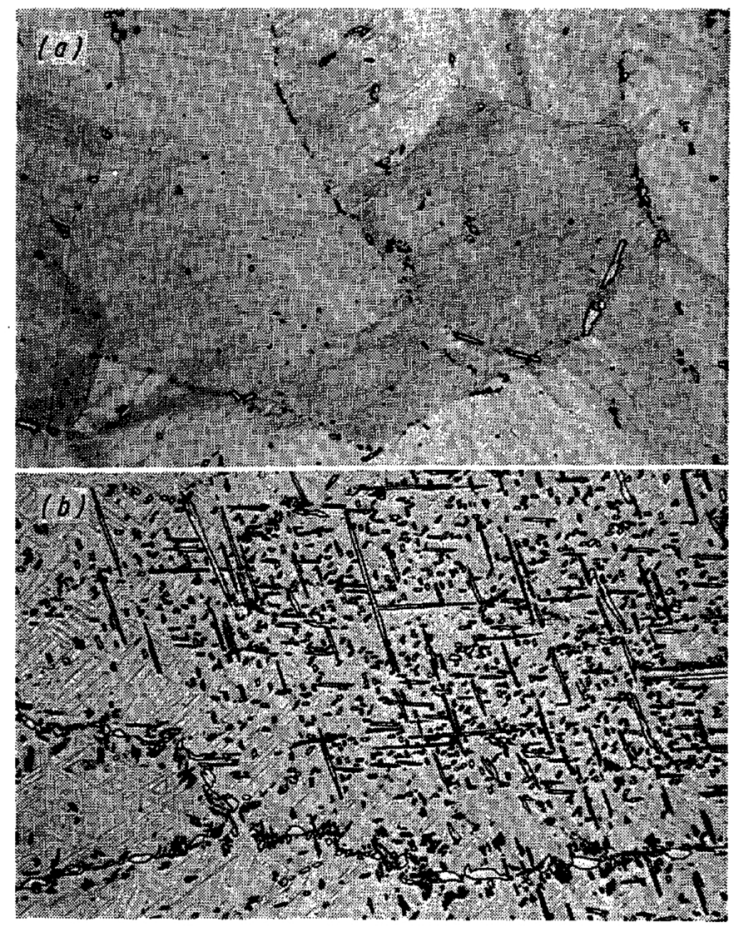

Photo. 1 Microstructures of NiTi containing 55 at $\%$ Ni. Specimens were heated up to required temperatures at a constant rate of $100^{\circ} \mathrm{C} / \mathrm{hr}$ after water-quenched from $1000^{\circ} \mathrm{C} .(\times 250)$

(a) water-quenched from $600^{\circ} \mathrm{C}$

(b) water-quenched from $800^{\circ} \mathrm{C}$

Etchant: 5 parts $\mathrm{HF}, 15$ parts $\mathrm{HNO}_{3}$ and 80 parts $\mathrm{H}_{2} \mathrm{O}$. 
The fact that the activation energy of the low temperature reaction is relatively low compared with that of nickel diffusion in some intermetallic compounds is preferable evidence to support (1) as the mechanism of the low temperature reaction.

\section{Existence of order-disorder transformation and eutectoid reaction in the NiTi phase}

As in the previous paper ${ }^{(1)}$, the existence of the order-disorder transformation which was reported first by Wang et al. ${ }^{(7)}$ has been supported by Zijderveld et al. ${ }^{(14)}$ but denied by Hirano and Ouchi ${ }^{(15)}$. Wasilewski et al. ${ }^{(16)}$ also have not supported the Wang's study. Recently, Iwasaki and Hasiguti ${ }^{(17)}$ reported that the evidence showing the existence of the transformation was obtained in the observation of an antiphase boundary using an electron microscope. On the stability of the NiTi phase at ambient temperature, a series of studies initiated by Duwez and Taylor has been done by many investigators ${ }^{(18)}$. But there are still critical opinions ${ }^{(3)}$ of Koskimaki et al. and Wasilewski et al. concerning the existence of the eutectoid reaction. No definite evidence to justify their contentions has been obtained. Both the orderdisorder transformation and the eutectoid reaction act as a hardening mechanism in the alloy phase. In this section we discuss whether these reactions exist or not.

As illustrated in Fig. 5 the electrical resistivity of stoichiometric NiTi which was water-quenched and annealed for $100 \mathrm{hr}$ at $600^{\circ} \mathrm{C}$ to complete the ordering increases linearly with temperature and shows no anomalous change at temperatures from 200 to $1000^{\circ} \mathrm{C}$. When the sample reaches the transformation temperature, a discontinuous change in electrical resistivity must occur, because the electrical resistivity of the ordered phase is generally less than that of disordered one. Therefore, this result shows that no order-disorder transformation occurs or, if it occurs, the degree of order decreases gradually with temperature up to the melting point in the NiTi of stoichiometric composition.

This temperature $\left(600^{\circ} \mathrm{C}\right)$ also lies just below the eutectoid reaction temperature proposed by Koskimaki et al. ${ }^{(3)}$ If the eutectoid reaction exists and the decomposition of the NiTi phase proceeds completely as a result of annealing for $100 \mathrm{hr}$ at $600^{\circ} \mathrm{C}$, it is considered that the resistivity-temperature curve must show discontinuity at the eutectoid temperature because the electrical resistivity depends upon the NiTi phase and the products of eutectoid decomposition above and below the eutectoid reaction temperature, respectively. On the other hand, if the greater part of the NiTi phase still remains after heat-treatment, no anomalous change may be observed. From the result shown in Fig. 5, it should be considered that the decomposition does not occur at all, or a little portion of the NiTi phase decomposes without changes in the electrical properties.

If the eutectoid reaction occurs, the change in the electrical resistivity for $\mathrm{Ni}$-rich $\mathrm{NiTi}$ which is also given annealing for $100 \mathrm{hr}$ at $600^{\circ} \mathrm{C}$ must show the same tendency as in stoichiometric NiTi subjected to the same heat treatment. On the contrary, when the order-disorder transformation takes place at an intermediate temperature, the change in electrical resistivity with temperature should be a little complicated because of the dissolution of precipitates which appear during the annealing ${ }^{(13)(16)}$. In fact, the change in the electrical resistivity with temperature for Ni-rich NiTi is different from that of stoichiometric $\mathrm{NiTi}$ and the rapid increase in the electrical resistivity is observed around $700^{\circ} \mathrm{C}$. But the magnitude of the increase in the electrical resistivity was small and no discontinuous change in the electrical resistivity was detected. These results also give no evidence to support the existence of the orderdisorder transformation in Ni-rich NiTi.

4. Quench-hardening mechanism deduced from the results on electrical resistivity measurements

The evaluation of the results on electrical resistivity measurements for non-stoichiometric NiTi gives no evidence to confirm the occurrence of the orderdisorder transformation at an intermediate temperature. The existence of the eutectoid reaction is doubtful. The precipitation of $\mathrm{Ni}_{3} \mathrm{Ti}$ in the water-quenched state is also unlikely because of the relatively high activation energy. Hence, there is no effect of the precipitation on the hardness of the NiTi phase.

It should be considered that Ni-rich NiTi containing structure defects, in other words, the ordered NiTi phase containing excess nickel atoms is harder than stoichiometric NiTi. As the NiTi phase containing the structure defects can be carried over to room temperature by quenching, a significant increase in hardness is observed in contrast with the furnacecooled state in which Ni-rich NiTi consists of soft stoichiometric NiTi as a matrix and precipitated $\mathrm{Ni}_{3} \mathrm{Ti}$. The fact that $\mathrm{NiAl}$ and $\mathrm{CoAl}$ having a $\mathrm{CsCl}$ type structure and a wide homogeneity range show a drastic increase in hardness with increasing amount of structure defects seems to support this mechanism.

\section{Conclusions}

In order to clarify the cause of quench-hardening in $\mathrm{Ni}$-rich $\mathrm{NiTi}$ the relation between electrical resistivity and composition, and the changes in electrical resistivity at a constant rate of heating have been measured. On the basis of the results the phase diagram in the vicinity of the NiTi phase has been established and the hardening mechanisms acting on the Ni-rich NiTi have been discussed. These can be summarized as follows:

(1) On the Ni-rich side of the stoichiometry the electrical resistivity measured at room temperature increases with increasing nickel content for waterquenched specimens, but the resistivity remains constant for furnace-cooled specimens. Comparison of the result with the theoretically derived relation between electrical resistivity and nickel content by using three proposed phase diagrams with or without 
order-disorder transformation shows that the homogeneity range of the NiTi phase becomes narrower with decreasing temperature, hence revealing no eutectoid reaction, and that a superlattice exists over the entire temperature range investigated.

(2) A constant rate of heating experiments for the specimens having stoichiometric and non-stoichiometric composition which were given sufficient annealing for ordering exhibit no discontinuous change in electrical resistivity to support the existence of the order-disorder transformation and the eutectoid reaction.

(3) The electrical resistivity of water-quenched $\mathrm{Ni}$-rich NiTi increases with two distinct changes at 300 and $700^{\circ} \mathrm{C}$ on heating. The activation energies of these processes are obtained as $1.1 \mathrm{eV}$ and $3.7 \mathrm{eV}$ for low temperature and high temperature reactions, respectively. The activation energy of the high temperature reaction is comparable to that of nickel self-diffusion in Ni-rich NiAl. On the phase diagram the reaction occurring at that temperature. must be the precipitation of $\mathrm{Ni}_{3} \mathrm{Ti}$. The high temperature reaction, therefore, is the precipitation of $\mathrm{Ni}_{3} \mathrm{Ti}$.

(4) The interpretation of the results on the electrical resistivity measurements indicates that the existence of the order-disorder transformation and the eutectoid reaction is improbable and also the precipitation of $\mathrm{Ni}_{3} \mathrm{Ti}$ in the water-quenched state is unlikely to occur. Quench-hardening appearing in Ni-rich NiTi is, therefore, considered to be due to the quenched-in structure defects which are introduced by the deviation from the stoichiometric composition at the quenching temperature.

\section{Acknowledgment}

The authors would like to express their thanks to Mr. T. Negishi of Hitachi Metals Ltd. for his assistance throughout the investigation.

\section{REFERENCES}

(1) T. Suzuki: J. Japan Inst. Metals, 34 (1970), 337.

(2) J. H. Westbrook: J. Electrochem. Soc., 103 (1956), 54.

(3) Current papers concerning the eutectoid decomposition of NiTi phase are D. Koskimaki, M. J. Marcinkowski and A. S. Sastri: Trans. Met. Soc. AIME, 245 (1969), 1883, and R. J. Wasilewski, S. R. Butler and J. E. Hanlon: Met. Trans., 1 (1970), 1459.

(4) A. S. Sastri and M. J. Marcinkowski: Trans. Met. Soc. AIME, 242 (1968), 2393.

(5) A. C. Damask and G. J. Dienes: Point Defects in Metals, Gordon and Breach, New York, (1963), p. 151.

(6) G. F. Hancock and B. R. McDonnell: Phys. Status Solidi (a), 4 (1971), 143.

(7) F. E. Wang, W. J. Buehler and S. J. Pickert: J. Appl. Phys., 36 (1965), 3232.

(8) Y. Yamaguchi, D. A. Kiewit, T. Aoki and J. O. Brittain: J. Appl. Phys., 39 (1968), 231.

(9) S. R. Butler, J. E. Hanlon and R. J. Wasilewski: J. Phys. Chem. Solids, 30 (1969), 1929.

(10) Y. Yamaguchi, T. Aoki and J. O. Brittain: J. Phys. Chem. Solids, 31 (1970), 1325.

(11) L. Nordheim: Ann. Physik, 9 (1931), 607.

(12) J. Takamura: Point Defects and the Mechanical Properties of Metals, Ed. by Japan Inst. Metals, Maruzen, Tokyo, (1967), p. 65 (in Japanese).

(13) R. J. Wasilewski, S. R. Butler, J. E. Hanlon and D. Worden: Met. Trans., 2 (1971), 229.

(14) J. A. Zijderveld, R. G. de Lange and C. A. Verbraak: Mém. Sci. Rev. Mét., 63 (1966), 885.

(15) K. Hirano and K. Ouchi : J. Japan Inst. Metals, 32 (1968), 613.

(16) R. J. Wasilewski, S. R. Butler and J. E. Hanlon: Met. Sci. J., 1 (1967), 104.

(17) K. Iwasaki and R. R. Hasiguti: Ordered Alloys; Structural Application and Physical Metallurgy, Ed. by B. H. Kear, C. T. Sims, N. S. Stoloff and J. H. Westbrook, Claitor's Publishing Division, Baton Rouge, (1970), p. 169.

(18) For example, (15) and others listed below: P. Duwez and J. L. Taylor: Trans. AIME, 188 (1950), 1173; H. Margolin, E. Ence and J. P. Nielsen: Trans. AIME, 197 (1953), 243; D. M. Poole and W. Hume-Rothery: J. Inst. Metals, 83 (1954), 473; G. R. Purdy and J. G. Parr: Trans. Met. Soc. AIME, 221 (1961), 636. 